\title{
Forecast and optimisation device for the mode control of a pumping station
}

\author{
D. E. Babinovich \& E. A. Shutov \\ National Research Tomsk Polytechnic University, \\ Institute of Power Engineering, \\ Department of Industrial Electric Power Supply, Russia
}

\begin{abstract}
Pumping units of the country use more than 300 billion kWh of electricity annually, i.e. more than $20 \%$ of the whole amount of electricity generated by the electric power network of the country (Leznov, Saving energy in pumping installations, 1991). In accordance with the requirements of the energy efficiency law, consumers should save energy in their companies. Water supply companies face a problem of low efficiency of the main technological equipment, such as pumping units supplying water into the network, and sewage pumping stations. A possible solution of this issue might be the optimisation of energy consumption by selecting the most appropriate model for the pumping unit control. Generally, the accepted way of improving energy efficiency of pumping units is by the introduction of the variable frequency drive (VFD), which provides a significant reduction in electricity consumption.

However, this approach does not lead to the solution of another important problem, which is, the correspondence of a high tariff rate of electrical energy/power during a 24-hour period with the load diagram of pumping equipment. In order to solve this problem, various control systems for a pumping unit with optimisation of the energy consumption level and maintenance of the required level of water supply reliability have been analysed in publications. Such decisions may include, for example, the introduction of a Transmission Operations Optimizer with forecasting and optimisation units presented in Błaszczyka et al. "Optimal Pump Scheduling for, Large Scale Water Transmission System by Linear Programming" 2012, or the introduction of a pumping unit, depending on the level of electricity prices (He Zhang, Optimal
\end{abstract}


sizing and operation of pumping systems to achieve energy efficiency and lode shifting, 2011).

In the paper a virtual model of the pumping unit is analysed together with its introduction into the classic control system with a variable frequency drive and forecast and optimisation control. It is expected that the use of the pumping units' control systems along with economic planning will result in up to $26 \%$ cost reduction for the electrical power (EP) even with the growth of electrical energy consumption.

Keywords: energy saving, energy efficiency, pumping stations, electric energy consumption forecast, power load frequency control.

\section{Introduction}

In accordance with the Federal Law number 442 as of 01.05.2011 "On the functioning of retail electricity markets ...", depending on the peak power at the point of the balance differentiation a consumer must choose the most suitable price range (PR). At the moment, consumers with a maximum power usage of more than $670 \mathrm{~kW}$ are faced with a major dilemma. Since $1^{\text {st }}$ July 2013 it has become possible to choose either PR with hourly energy metering or PR with an hourly energy metering and planning. In addition, the requirements specified by a guaranteed supply company of EP to an industrial enterprise are not just limited to economic planning relations of the two parties regarding penalty charges for any usage variations to the purchased electric power. In accordance with the hierarchical stages of the EP market, a guaranteed supply company must comply with the interests of the grid and generating companies demanding load leveling. Usually these requirements are also imposed upon the final consumer of EP. For an industrial enterprise, this issue can be resolved only at the level of technological process by means of the introduction of energy-efficient process flows with an adaptation function and application of a forecasting device.

The choice of a forecasting method depends on several factors: the electrical load diagram of an object, the availability of stable cycles in the work of processing equipment, the presence of abnormal values of EP consumption and "noise" in the load diagram, the presence of a large number of factors influencing electricity consumption. The implementation of forecasting in water supply facilities has been well analyzed and discussed in the following literature references [7-10].

Due to the fact that water supply companies consume a significant amount of electricity in the region, the maximum price for electricity is correlated with a water consumption schedule. In order to break this correlation, an optimisation and forecasting unit must be introduced into the control machine for a pumping unit. Due to this, electric energy consumption costs will be reduced in peak load hours.

In the paper, a forecast and optimisation controlling device has the following main task: to reduce the consumption costs of EP by taking into account the correlation of prices for EP within 24 hours and during formation of the operational schedule for pumping units. 


\section{Main level heading}

As stated above, with regard to the pumping units of the water supply chain, a conventional decision for the optimisation of the technological process is the use of a variable frequency control in a pumping unit with a vector or adaptive control [11]. Using the example of service water lifting, technical and economical aspects of such an approach can be evaluated. The object for research is the pumping unit Grundfos $N B$ 80-200/211 (Fig. 1) $45 \mathrm{~kW}$ with engine drive MJ225-2-55F [12] and equipped with a frequency converter (FC).

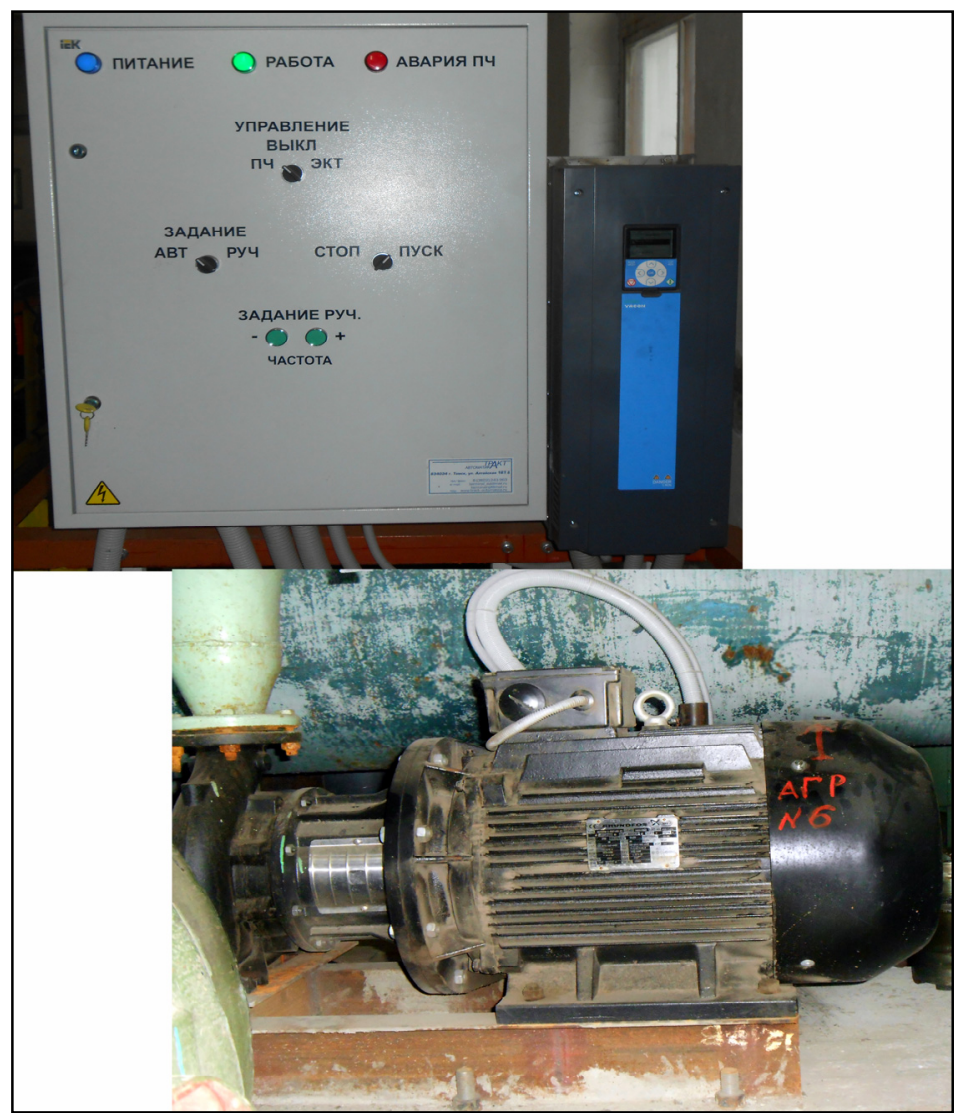

Figure 1: The engine drive MJ225-2-55F equipped with a frequency converter.

This pumping unit is a part of the technological equipment of the $3^{\text {rd }}$ elevation pumping plant and supports the necessary pressure of the service water (7 atm) during its transfer from the place of the direct lift (pumping filtration plant) to the consumer, which is a peak load auxiliary boiler station (PAB). In this case, 
the pressure level at PAB is 5-5.5 atm. Flow and pressure control is made on the basis of reading the meters that are installed at the inlet and outlet of the station.

The daily schedule for service water consumption and cost of electricity for $\mathrm{PAB}$ is presented in Figure 2.

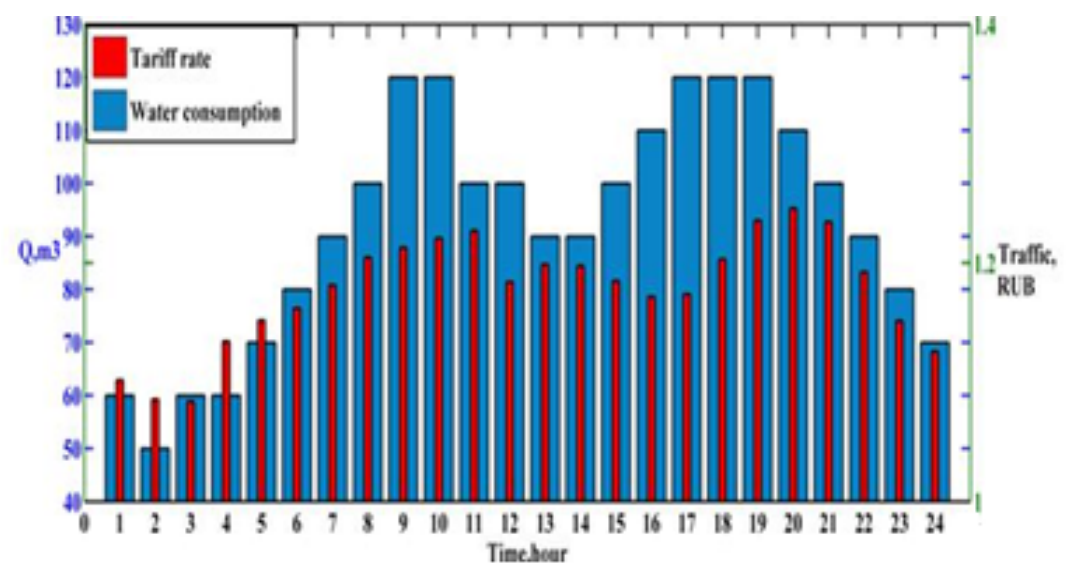

Figure 2: Load diagrams the daily schedule for service water consumption and cost of electricity for PAB.

From this graph, a clear correlation between the price of electricity and power consumption of the pump unit can be seen. Due to the fact that the $3^{\text {rd }}$ elevation pumping plant, under the terms of the rules of the retail market, receives electrical energy using a binomial rate (price range 6); such correlation between price and EP consumption leads to the growth of $\mathrm{kWh}$ rates and also directly for power (network and power purchase). In the case of such payment system, each hour of the day has a set cost of consumed EP (Fig. 2). This factor contributes significantly to the increase in water production and transportation costs.

But if it is possible to adjust the operation of equipment within the production technology, then there will be an opportunity to transfer the maximum load to the hours of minimum cost for EP. For water supply companies, such a situation is possible when working with a storage tank or when the entire production can be reduced to a tank which is under a pressure difference.

The objective function of the optimisation of an enterprise is a minimum cost for the EP acquisition while maintaining the technological effectiveness of the production.

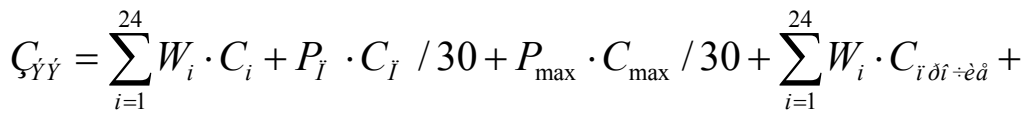

$$
\begin{aligned}
& +\sum_{i=1}^{24} W_{i}^{+} \cdot C_{i}^{+}+\sum_{i=1}^{24} W_{i}^{-} \cdot C_{i}^{-} \rightarrow \min
\end{aligned}
$$


where

$W_{i}$ - energy consumed per hour, $\mathrm{kWh}$;

$C_{i}-$ EP rate per hour, RUB/kWh;

$P_{\Pi}$ - power, paid for on the wholesale market (defined in accordance with the peak hour of the power system), $\mathrm{kWh}$;

$C_{\Pi}$ - rate for power purchased by a consumer at the threshold level of nonregulated prices, RUB/kWh per month;

$P_{\max }-$ network power, paid by the consumer for the power for the services of EP transfer, kWh (defined as the maximum capacity of the planned peak hours approved by OJSC "SO UES", depending on the consumer price zone);

$C_{\text {max }}$ - power rate for the EP transfer services, RUB/kWh per month;

$C_{\text {nрочие }}$ - rate for other services, which are an integral part of the supply process for electric energy and power for the billing period, $\mathrm{RUB} / \mathrm{kWh}$;

$W_{i}^{+}-$value of the excess of the actual volume of electricity consumption over the planned value, $\mathrm{kWh}$;

$C_{i}^{+}$- differentiated by the hours of the billing period unregulated price for electricity on the wholesale market, defined by a commercial operator of the wholesale market based on the results of the competitive procedure of applications for balancing the system with respect to the exceeded volume of the actual consumption over the planned consumption per hour $(i)$ of the billing period;

$W_{i}^{-}$- value of the excess of the planned volume of electricity consumption over the actual value, $\mathrm{kWh}$;

$C_{i}^{-}$- differentiated by the hours of the billing period unregulated price for electricity on the wholesale market, defined by a commercial operator of the wholesale market based on the results of the competitive procedure of applications for balancing the system with respect to the exceeded volume of the planned consumption over the actual consumption per hour $(i)$ of the billing period.

For the purposes of taking into account the joint impact on electricity efficiency of the optimisation levels of the technological process (the level of the electric drive) and the production process (the level of planning and economic indicators), the virtual model was created in a software environment MATLAB, presented in Figure 3.

The studied model of the pumping station operates in accordance with the equipment catalogued data included in the real technological process (Fig. 1) with up to $5 \%$ accuracy. 


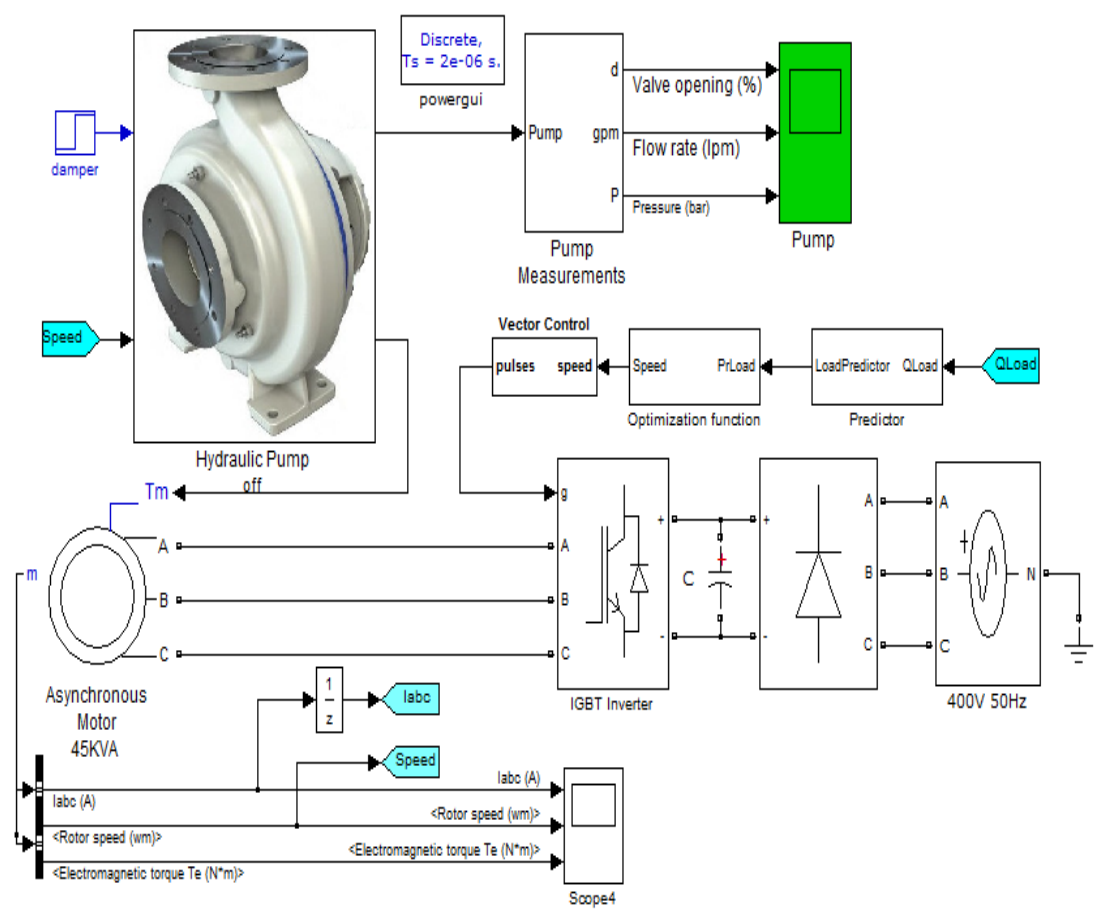

Figure 3: Simulation model of the $3^{\text {rd }}$ elevation pumping plant.

The highest hierarchical level of coordination - SCADA (Supervisory Control and Data Acquisition) system (e.g., TRACE MODE) was added into the classical algorithm of the vector control of FC. Functionally the SCADA system remembers meter readings at the inlet and outlet of the $3^{\text {rd }}$ elevation pumping plant and carries out the operation of historical data preparation for the forecast procedure. Technological processes of EP consumption ("Tomskvodokanal" LLC) are subject to cyclical, functional and casual trends, out of which the most predictable are circular dependencies (usually daily):

- Cyclic dependencies comprise $70-80 \%$ of all usage variations from the EP consumption process; for example, one of the most significant cyclical factors is time of day, day of the week and length of daylight.

- Consistent patterns of the functional aspect: their share is about $10-15 \%$ of the total amount of usage variations. This group includes usage variations, which can be explained by known and relatively predictable production factors: such as air temperature, the volume of the production, etc.

- Random trends: their contribution to the overall process is small, but the deviation amplitude can be quite significant. Therefore, the probabilistic characteristics of the relevant phenomena should be determined for the random trends [12]. 
Selected time frames, which are based on the principle of a typical day of the week and a season, enter the unit Predictor of the MATLAB model. In order to receive projected values, the neural networks method is used; it is a powerful tool for creating accurate forecasts with a small prediction horizon. An adequate prediction model of EP consumption for each hour of the day with the accuracy of $0.55 \%$ was created using a three-layer neural network based on the multilayer perception scheme. The accuracy for a medium-term forecast was calculated based on the method of the average value from the forecast horizon.

The part called Optimisation function minimises the target function. The operation mode of the pump unit is changing in such a way that it will provide minimal EP acquisition costs while ensuring produceability of the water supply process for PAB with service water [13].

When using a water tank and implementing an optimisation unit, the mode change of the EP consumption takes place for the hours of minimum and maximum load in the load diagram:

- during the hours of minimum load of the power system, the tank is filled up and due to this the EP consumption increases for the pumping unit in comparison to the standard control circuit of a pumping unit with VFD;

- during the peak load hours of the power system, the pumping unit consumes minimum EP and PAB carries the water flow from the storage tank.

Thus, there is a decline in the volume of electric energy and power purchase at the maximum price and an increase in the amount purchased at the lowest price.

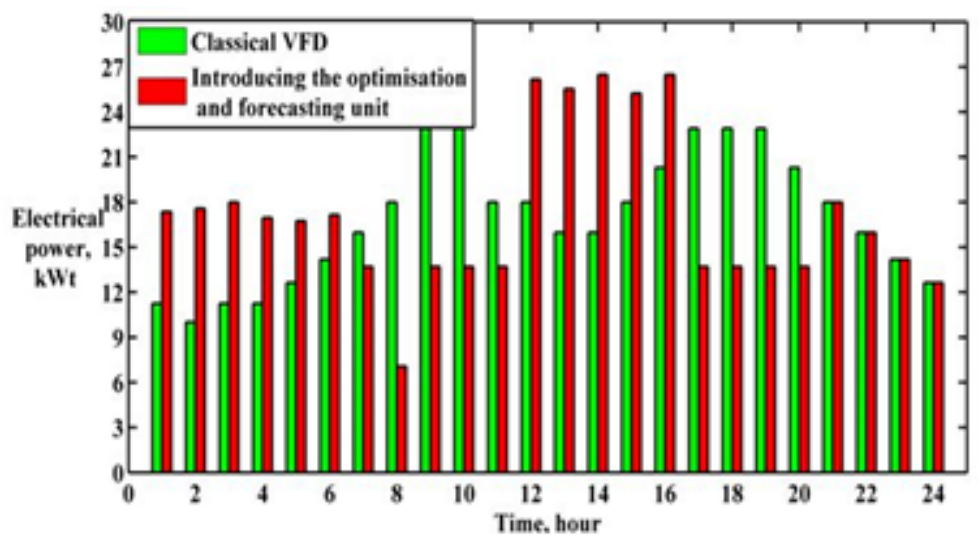

Figure 4: Load diagrams in the case of a classical VFD and when introducing the optimisation and forecasting unit.

Fig. 5 shows an EP consumption graph for the incorporated optimisation and forecast device for the $3^{\text {rd }}$ elevation pumping plant and the tariff amount per hour for the $6^{\text {th }} \mathrm{PR}$.

As can be seen from the graph, in the hours of peak value of EP and peak power value (8.00) the load is changed using the optimisation unit and the 
consumer pays much less for the electricity consumed in the given time intervals than ever before.

For example, earlier the EP cost was 21.67 RUB in the case of the classical way of controlling a pumping unit with VFD for 8.00 hour; and for the entire load curve, the price for the power purchase was 158 RUB and 540 RUB for the network power. When implementing VFD with optimisation and forecasting, the EP cost for 8.00 hour was 8.52 RUB (a $61 \%$ cost reduction), the value of powerpurchase was 62.32 RUB (a $60.6 \%$ cost reduction), the value of the network power was 323.12 RUB (a 40\% cost reduction) [13].

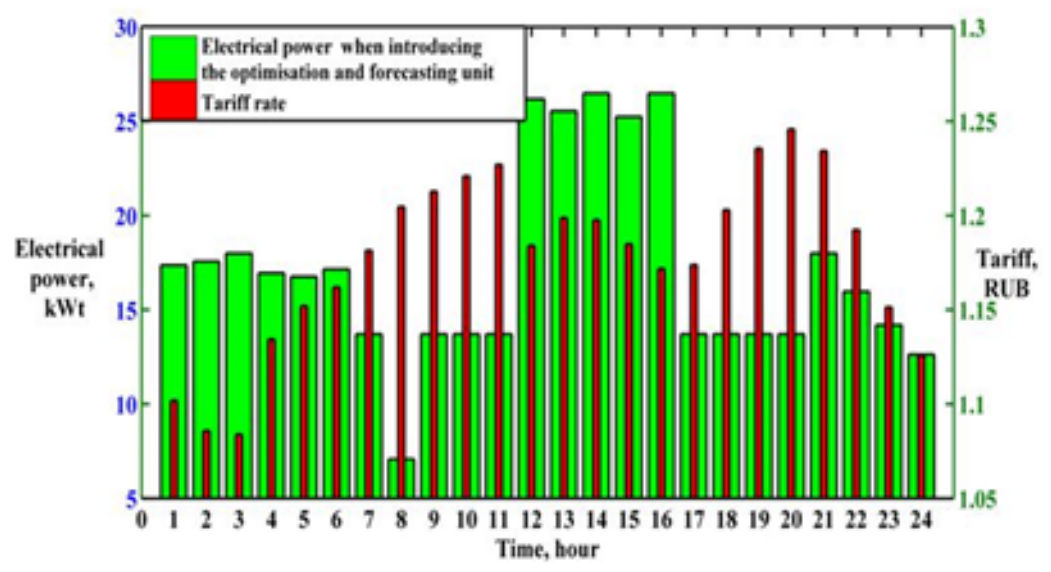

Figure 5: Daily EP consumption and tariff rate diagram.

When using the optimisation and forecast device, the full cost for EP consumption is defined by the formula (1)

Optimization results, depending on the method of the pump control, are summarised in Table 1:

Table 1: Optimisation results.

\begin{tabular}{|c|c|c|}
\hline Method of control & $\begin{array}{c}\text { EP consumed per } \\
\text { day, } \mathrm{kWh}\end{array}$ & $\begin{array}{c}\text { EP costs per day, } \\
\text { RUB }\end{array}$ \\
\hline Varying the speed of a pump & 406.37 & 1180.7 \\
\hline $\begin{array}{c}\text { Varying the speed of a pump using } \\
\text { the optimisation function and } \\
\text { consumption forecast }\end{array}$ & 411.2 & 870.58 \\
\hline
\end{tabular}

In this case, taking into account the economic planning, the payment order for EP with a guaranteed supply company and a forecast device, provides an opportunity for the industry to reduce costs for the EP purchase by $26 \%$ even with the growth in electric energy consumption. 


\section{Conclusion}

According to the research results, the following conclusions can be drawn:

- forecast and optimisation control together with the traditional slave control systems establishes a new order of relationship between the change in the tariff rate and the operation mode of a pumping unit;

- at this stage of the retail market development, there is an increase in the EP cost for the usage variations and at the same time there is a significant cost increase for the network power and power purchase. The forecast in this case is not just an element of EP consumption planning for the data transfer to a guaranteed supply company, but also as an important factor in the technological process control.

\section{References}

[1] Leznov B.S., Saving energy in pumping installations, Energoatomizdat: Moskow, 1991.

[2] Reynolds L.K., Bunn S. (eds), Improving energy efficiency of pumping systems through real-time scheduling systems, Integrating Water Systems - Boxall \& Maksimović (eds), Taylor \& Francis Group, London, pp. 325329, 2010.

[3] Zagirnyak Mykhaylo, Korenkova Tetyana, Alieksieva Iuliia, Energy and resource saving control system for pumping station, Przeglad Elektrotechniczny, R.89 NR 2b/2013, pp. 76-79.

[4] Kaya D., Yagmur E., Energy efficiency in pumps, Energy Conversion and Management, vol. 49, pp. 1662-1673, 2008.

[5] Jacek Błaszczyka, Andrzej Karbowskia, Kamil Krawczyka, Krzysztof Malinowskia, Alnoor Allidinac, Optimal Pump Scheduling for, Large Scale Water Transmission System by Linear Programming, Journal of Telecommunications and Information Technology, 3/2012, pp. 92-96.

[6] He Zhang, Optimal sizing and operation of pumping systems to achieve energy efficiency and lode shifting, April 2011, http://upetd.up.ac.za /thesis/available/etd-09222011-110333/unrestricted/dissertation.pdf

[7] Mordecai Feldman, Aspects of Energy Efficiency in Water Supply, Proceedings of the $5^{\text {th }}$ IWA Water Loss Loss Reduction Specialist Conference 26-30 April Cape Town South Africa pp. 85-89, 2009.

[8] Simon Bunn, P.E. Khos Ghaderi, Cary Hillebrand, Utilizing Energy and Demand Forecasting as a Tool to Develop Energy Procurement Strategies Presented at the American Water, Works Association, DSS section conference in Phoenix, AZ in September 2006.

[9] Water Consumption Forecasting to Improve Energy Efficiency of Pumping Operations, http://www.waterrf.org/PublicReportLibrary/91189 .pdf

[10] Ionescu Gheorghe - Constantin, GLIGOR Emil, Dan Florin, Ionescu George-Lucian, Electric energy consumption forecast within the waste 
510 Energy Production and Management in the 21st Century, Vol. 1

water treatment plant Oradea, Journal of applied engineering sciences vol. 1(14) issue 4_2011.

[11] Leznov B.S., Methodology to evaluate the effectiveness of the controlled drive in the water and sewer pump stations, Mashinostroenie: Moskow, 2011.

[12] Mallat S. A theory for multiresolutional signal decomposition: the wavelet representation, Pattern Analysis and Machine Intelligence, N7, pp. 674693, 1989.

[13] Pricing for legal entities, Tomskenergosbit Web Site, http://ensb.tomsk.ru /corporate_banking/rates_and_prices/ 